\title{
Cultural Introduction in Teaching Chinese as a Foreign Language
}

\author{
Zhe $\mathrm{Li}^{1, \mathrm{a}}$, Wenlan Zhao ${ }^{2, \mathrm{~b}}$, Hang Wang ${ }^{3, \mathrm{c}}$ \\ ${ }^{1}$ College of International Exchange, Bohai University, Jinzhou, 121013, China \\ ${ }^{2}$ College of Foreign Languages, Bohai University, Jinzhou, 121013, China \\ ${ }^{3}$ College of Engineering, Bohai University, Jinzhou, 121013, China \\ a503412508@qq.com, b724222790@qq.com, 'bhdxwanghang@163.com
}

\begin{abstract}
Keywords: teaching Chinese as a foreign language; cultural introduction; principles; methods; contents; strategies
\end{abstract}

\begin{abstract}
The development of teaching Chinese as a foreign language and the dissemination of the excellent culture of the Chinese nation are of great significance to the improvement of China's international influence. Teaching Chinese as a foreign language is not only a language teaching, but also is a cultural teaching. The unity of language teaching and culture teaching is very important characteristic in the teaching of Chinese as a foreign language. It can meet the needs of Chinese learners to understand Chinese culture, promotes the teaching of Chinese as a foreign language, and improves the international status of Chinese. In order to improve the effect of cultural introduction, this paper analyzes the principles, methods and contents of cultural introduction, and puts forward the strategy of cultural introduction. Specific strategies include: pay attention to the introduction of implicit culture, improve the quality of teaching materials, to play the role of teachers of Chinese as a foreign language.
\end{abstract}

\section{Introduction}

Teaching Chinese as a foreign language is the cause of the country and the nation, and is an integral part of the overall situation of the country's reform and opening. Development of teaching Chinese as a foreign language, can promote Chinese culture spread the world, spread the excellent culture of the Chinese nation, enhance mutual understanding and friendship among people of the world and China, cultivate more friendly people in China, expand exchanges and cooperation in all aspects of China and the world economy and culture, has important strategic significance to improve Chinese effect in the international arena [1]. The progress of mankind has entered twenty-first Century, by adding WTO, China influence in the world economic development further increase, China development and progress provide a great impetus to the development and a rare opportunity. The teaching of Chinese as a foreign language is bound to achieve greater development in the new century, the Chinese language will gradually become an important language of international exchanges, more countries and regions use it in the world. It becomes an important tool for the development of political, economic, cultural and educational exchanges between countries.

Language is the carrier of thought and the carrier of culture. Learning a language, is also learn a culture related to this language; teaching a language is also teach the language bearing the culture. The work of cultural communication in teaching Chinese as a foreign language should not only understand the nature of language and culture and its relationship, but also seek the content and way of cultural introduction. Culture determines the existence of people, including self-expression, feelings of expression, way of thinking, behavior and problem-solving methods. The teaching of culture in the second language teaching is mainly the deep culture which influences the communication protocol, the way of life, the way of thinking and the values. Teaching Chinese as a foreign language is both a language teaching and a cultural teaching. The unity of language teaching and cultural teaching is a very important feature of teaching Chinese as a foreign language. Teaching Chinese as a foreign language, fundamentally, is to enable learners to master the language of this tool, and develop their ability to use language skills. To achieve this goal, we must pay 
attention to the cultural factors contained in language teaching, full of cultural factors on the second language acquisition is very beneficial, can play a role in promoting and deepening.

\section{Importance of Cultural Teaching}

Chinese has its own special laws, reflects the culture with other countries and peoples, has brought difficulties to the language learning. Do not understand the customs of the Chinese, in particular, do not understand the communication etiquette and rules, it is difficult to accurately use Chinese for communication. Do not grasp the cultural connotation of the language and related social customs background, it is difficult to master the essence of Chinese. From the perspective of language learning and language teaching, we must study the relationship between language and culture, because language understanding and language use are inseparable from certain cultural factors. Therefore, teaching Chinese as a foreign language are both a language teaching and a cultural teaching. Language teaching and cultural teaching become a unified, is a very important feature of teaching Chinese as a foreign language.

It has great importance to carry out cultural teaching in teaching Chinese as a foreign language. First, it is necessary to meet the needs of Chinese learners to understand Chinese culture. More and more people learn Chinese in the world. Their language knowledge is not only stop at the theoretical level, but also want to understand the Chinese culture, so that the knowledge structure is more abundant; second, promotes the teaching of Chinese language needs, simple Chinese teaching has been unable to achieve significant results, boring Chinese theory has denied the learners patience and enthusiasm; pay attention to the cultivation of learners' cultural quality and nurture with the teaching of Chinese at the same time, so that both language and culture, which is in line with the need for in-depth reform of teaching Chinese as a foreign language; third, the needs of Chinese culture to the world and further improve the international status of Chinese, conform to the global trend of Chinese hot, carry forward the fine traditional Chinese culture, promote the Chinese civilization to the world.

\section{Principles of Cultural Introduction}

Teaching Chinese as a Foreign Language is the principle of teaching activities. In order to make the second language learners understand and master the Chinese culture and promote the smooth development of the language teaching activities, when teaching in language, the cultural introduction should follow the following principles:

(1) Comparative principle. Different countries have different cultures, cultures vary widely, there is no merit of the points, but have a unique charm. Cultural introduction to stand in the height of the world to find the Chinese culture and the purpose of language in the national culture between the same and different, in the same place to understand the link between cultures, in the difference between the cultural differences, not only able to students who understand the particularity of Chinese culture, but also to further understand their own country's culture. Only the real difference between the different, understand the different cultures of different countries in order to better adapt to cross-cultural communication.

(2) Stage principle [2]. Language learning is the same as other knowledge learning, from shallow to deep, from simple to complex, with obvious phased features. Therefore, the introduction of culture in teaching Chinese as a foreign language, according to the actual language level of students and comprehend the ability to grasp the appropriate level of Chinese proficiency in the standard classification of the level of synchronization. For example, in the initial stage of Chinese language learning, we should let them know the most common cultural phenomenon, to impart advanced language and culture knowledge, do not meet the language teaching and students to understand the actual situation, not the effect of cultural import.

(3) Permeability principle. The cultural introduction in the teaching process is not simply instilling, but through the teacher's words and deeds and other teaching activities, consciously to the students with hints, or in language communication and emotional expression reflected, so that 
students secretly access to cultural knowledge. A few minutes before the class is usually a cultural import, including cultural reasons, background and social performance. On the one hand to attract students attention, improve student interest; the other hand, through the unconscious introduction, gradually affect the student's knowledge structure, easy to be accepted and applied.

(4) Communication principle. The ability of language communication is the method of obtaining cultural knowledge, and the introduction of the symbol of mainstream culture in teaching can enhance students' ability to recognize language and distinguish language and culture so that they can see the traditional and behavioral rules of Chinese culture more objectively. Success in cultural communication. But also the philosophy, life standards and attitude of life and other aspects of the proverbial as a cultural information into, help students understand some of the more profound cultural knowledge, so as to broaden their horizons, enhance cross-cultural communication skills.

(5) Appropriateness principle. According to the teaching tasks and teaching objectives, targeted to solve the cultural barriers in language teaching, and in the appropriate extension of the cultural background knowledge, so that when similar problems can be understood. Chinese culture has a long history, broad and profound, only moderately imported, in order to effectively serve the teaching, play a multiplier effect. Cultural content must be carefully selected, highlight the focus. The contents of the import can not be too much, otherwise it will take up too much language teaching time; but not too little, otherwise the learners do not know the cultural factors, the impact of cross-cultural communication smoothly.

\section{Methods of Cultural Introduction}

The introduction of culture in teaching Chinese as a foreign language should not only benefit foreign students' learning of Chinese, but also stimulate interest in Chinese culture. Therefore, the introduction of culture in teaching Chinese as a foreign language, on the one hand to meet the interest of foreigners in Chinese culture, on the other hand can serve the Chinese language teaching. The specific method is as follows:

(1) Introduction of Chinese teaching. Chinese characters can best reflect Chinese culture. Chinese teaching should be easy to difficult, began to teach students simple and easy to understand the Chinese characters, and then slowly into the relatively common, but also contains the representative of the cultural vocabulary. Chinese vocabulary contains a rich culture, explain the need to explain the load of cultural background knowledge. The structure of Chinese words embodies the characteristics of the nation's overall thinking and dialectical thinking. Some vocabulary embodies the Chinese people's way of life and customs. Chinese vocabulary is large, mostly two-syllable words, which is the Chinese language thinking and unique cultural mentality of the performance. Through this way, can stimulate their interest in Chinese culture, spread out the profound Chinese culture.

(2) Introduction of reading literary works. Learning any language requires a lot of reading training. Reading can increase vocabulary, cultivate language, get a lot of cultural information. Teachers in the selection of Chinese reading materials for students, there must be a certain relevance, the material set a certain number of cultural information points, in the daily communication is more common, and with the Chinese people's living customs, thinking habits, historical origins, cognitive Methods, values and aesthetic taste and other closely related content, so that students in the way of thinking to move closer to the Chinese people, feel the charm of Chinese culture.

(3) Introduction of cultural lecture [3]. When the Chinese language level reaches a certain level, it is necessary to study Chinese culture more systematically and more deeply. Teachers can organize some lectures related to Chinese cultural knowledge and provide students with a complete system of knowledge in a short time. Teachers also need to guide students to collect and collate information to encourage the exchange of relevant topics, change the passive learning to take the initiative to learn, deep the understanding of Chinese culture, improve the cultural import effect. The introduction of cultural lectures can also use comparative law to attract students' interest by comparing the differences between the two cultures. 
(4) Introduction of watching the film and television works [4]. Film and television works are the most abundant resources in the language teaching of the information age. As a combination of auditory and visual arts, the students can create a lively scene and a realistic language atmosphere for students to be immersive a feeling of. Film and television media as a means of teaching, help to strengthen students' listening to Chinese language vocabulary ability. Film and television media to provide a large number of language and cultural information, students can capture their own interest in the knowledge points, is conducive to the absorption and digestion of knowledge.

\section{Contents of Cultural Introduction}

There are many cultural contents that need to be imported for teaching Chinese as a foreign language, which mainly includes the following four aspects:

(1) Vocabulary culture [5]. Vocabulary is the basic composition of language, records the cultural development of the historical track and rich results. The difference in terms of each language reflects the cultural characteristics of the language, customs, and activities of the language. Chinese characters are unique charm of the text, the composition of the word culture is very rich, for the Chinese people of all national common, is a long history of Chinese culture witness, but also an important symbol of Chinese civilization. As the ideographic characters of Chinese characters, almost every word is different to reflect the Chinese people's daily life. Therefore, mastering the vocabulary culture is a prerequisite for learning Chinese culture.

(2) Thinking culture. Thinking culture is a culture of different ways of thinking and habits. Different cultures of people on the outside world there are differences in the way of thinking, thinking patterns must also be different. Different cultural differences in thinking, will lead to language expression and behavior of the different, lack of understanding of this, cross-cultural communication process will have a conflict. The way of thinking is linked to different cultural areas, with the characteristics of a particular culture. Language, culture and thinking are dialectical unity, each language corresponds to a specific culture, and a specific culture to a certain extent, determines the way of thinking. Therefore, language learners need to further understand the values, ways of thinking and psychological characteristics.

(3) History and culture [6]. China's history and culture are the national culture of Chinese civilization evolution, reflect the national characteristics and style of national culture, are the national history of various ideology and culture, the concept of the overall representation of the shape of the Chinese nation and its ancestors, for the Chinese nation Inherited the development, with distinctive national characteristics, have a long history, profound connotation of the traditional fine culture. Chinese history and culture in addition to the core content of Confucian culture, but also contains other cultural forms. China's history has a long history, the expression of Chinese and speech composition has far-reaching impact, so learn good Chinese, in-depth understanding of Chinese, it is very important to introduction Chinese history and culture.

(4) Communication culture. Communication culture is through the social interaction between people and people, to convey information and exchange ideas, to achieve a certain purpose of social activities reflected in the cultural phenomenon. Including greetings, greetings, thanks, apologies, farewells, calls, requests and invitations, as well as topic selection, taboo, euphemism, social customs and rituals. Chinese communication is a reflection of culture, communication often take their own compared with others, according to the other age, status, family and their relationship with their own situation, to decide how to say and how to do. Foreigners on the Chinese people to inquire about their own situation is very disgusted, that is interfering with their own lives, snooping their own privacy. Therefore, the introduction of communicative culture can avoid cross-cultural communication errors.

\section{Strategies of Cultural Introduction}

In order to improve the effect and efficiency of cultural introduction, combined with years of teaching practice, this paper proposes the following strategies: 
(1) Focus on hidden culture. Explicit culture is explicit, in the cultural surface, static, easy to understand and master the cultural phenomenon. Hidden culture is implicit, in the cultural bottom, dominate the language behavior, difficult to detect and capture the cultural phenomenon. Hidden culture is a psychological level, involving people's thinking, faith, ideals, world outlook, values, personality patterns and aesthetic taste and so on. Hidden culture permeates all levels of dominant culture and controls people's thoughts and behaviors. Relative to the dominant culture, hidden culture is more difficult to import, so the teaching should focus on the introduction of hidden culture. Hidden culture contains a lot of content, mainly into the Chinese people's national concept, national psychology and thinking and so on.

(2) Improving the quality of teaching materials. Teaching materials is the specific basis for teachers to educate and educate students is an important tool for students to acquire systematic knowledge and develop intelligence, must play the role of teaching materials. The teaching materials of Chinese as a foreign language have their particularity, and improve the quality through the following ideas: taking into account the basic and academic, teaching materials are usually from the training objectives, teaching the basic knowledge of the subject. But the basic and academic is not contradictory, should be the forefront of theoretical research in a simple way to integrate into the textbook to pay attention to cultural differences, to guide students in the mother tongue culture and Chinese culture contrast thinking, try to get rid of latent culture contrast With narrow thinking to simplify the rich content; focus on fun, cultural materials in the interesting direction has a unique condition, play this advantage, through the fun to attract students.

(3) Playing the role of teachers of Chinese as a foreign language [7]. Teachers are the leading teaching, is the classroom designers, leaders and important participants, teaching Chinese as a foreign language must give full play to the dynamic role of teachers. In the teaching process of cultural introduction, teachers should fully mobilize the enthusiasm of students, pre-class students to prepare relevant cultural knowledge, the classroom by the students try to explain and improve the language organization and expression of students; reflected in the teaching attitude and teaching methods Teachers and teachers on the basis of China's image, to reflect the good quality of teachers and teaching quality, when the Chinese culture and other cultures conflict, to take a compatible attitude, do not deny other culture.

\section{Acknowledgement}

This work is supported by social science fund project of Liaoning province: Research on bidirectional cultural teaching in college English writing teaching (L15BYY008).

\section{References}

[1] Ministry of education of the people's Republic of Chinag, "Brief introduction on teaching Chinese as a foreign language," http://www.moe.edu.cn/gjs_left/mo587.html, 2017-3-1.

[2] J. Y. Chen, "On the principle of cultural introduction in teaching Chinese as a foreign language," Examination weekly, vol. 5, no. 82, pp. 48-48, 2011.

[3] J. Guo, "Introduction of culture in Chinese as a foreign language," Journal of Hubei Institute of Technology, vol. 33, no. 3, pp. 111-112, 2013.

[4] J. Zhang, "Introduction of culture knowledge in teaching Chinese as a foreign language," Master's degree of Zhengzhou University, 2014.

[5] Step by step paper net, "Analysis of the content of culture introduction to Chinese as a foreign language," http://www.lunwenup.com/jiaoyufanwen/40221.html, 2017-3-1.

[6] Y. Guan, "Chinese history and culture teaching in Chinese as a foreign language," http://www.xzbu.com/1/view-6429124.htm, 2017-3-1.

[7] J. Zhang, "Study on the introduction of culture in teaching Chinese as a foreign language," Master's degree of Inner Mongolia Normal University, 2013 